\title{
The Japanese-American: A Cross-Cultural, Cross-Sectional Study of Sex Guilt
}

\author{
Paul R. Abramson \\ University of California, Los Angeles
}

AND

JOHN IMAI-MARQUeZ

University of Michigan

\begin{abstract}
The purpose of the present investigation is to examine cultural differences in sexual standards and the process of acculturation, using three generations of Japanese-Americans and matched Caucasian-American controls. JapaneseAmericans were selected for study because of their generational, ethnic, and social structure. The present study hypothesized a change in sex guilt across the three generations of Japanese-Americans, approximating a bicultural adaptation. The results indicated that although the Japanese-American is a highly acculturated ethnic group, significant cross-cultural differences continue to emerge, especially among Japanese-American women. Furthermore, where gender differences do occur, they favor greater flexibility for men, in general, and for Japanese-American men in comparison to Japanese-American women. Finally, the results suggest that pronounced cultural changes in sexual standards have occurred over the past 70 years.
\end{abstract}

Kinsey (Kinsey, Pomeroy, \& Martin, 1948; Kinsey, Pomeroy, Martin, \& Gebhard, 1953) believed that cultural variability in human sexual behavior was a primary indicant of the effectiveness of social pressures and restraints. Moreover, Ford and Beach (1951) suggest that the impact of learning upon human sexual behavior is best understood within the frame of reference provided by the society of which the individual is a member. In both of these cases, it is assumed that society shapes its

This research was supported in part by a University Research Grant and Biomedical Research Support Funds from the University of California, Los Angeles. The authors wish to express sincere thanks to Charles Y. Nakamura, Harry H. L. Kitano, and Neil Teng for their comments on the manuscript and to Virginia Johnson, Euni Yamaki, Grace Iino, and Irene Sunabe for their assistance in data collection. Requests for reprints should be sent to Paul R. Abramson, Department of Psychology, UCLA, 405 Hilgard Ave., Los Angclcs, CA 90024. 
members through cultural definitions of what is sexually appropriate or pleasurable, which in turn has the effect of creating sexual standards which reflect cultural sanctions (Abramson, 1982).

Given that human sexual behavior is the product of an inordinately complex social structure, it should not be surprising to find that researchers have concluded that sexual behavior is strongly influenced by social norms. Basically, these researchers have discovered that every society develops preferential standards of conduct which are transmitted from one generation to the next. Furthermore, although there is interindividual variation within every society, it is also assumed that each member of society will behave in a manner which is consistent with the overall objectives of that culture. In other words "the culture provides, through the habits of its members, the major learning conditions for the maturing individual" (Ford \& Beach, 1951, p. 268).

The significance of social norms is apparent from two perspectives: cross-cultural variation and cross-species variation. Where cross-species variation is concerned, differences between humans and other animals are attributable to either biological changes accompanying human evolution or cultural standards which have significantly modified basic inherited tendencies. Furthermore, despite the evidence for evolution, Ford and Beach conclude that interspecies differences are most closely related to cultural modifications.

Further evidence of the significance of social norns comes from the work of Davenport (1965, 1976). Davenport (1976) suggests that the existence of time when human sexual behavior was socially unrestrained is highly improbable. He argues that even though sexual behavior owes considerable allegiance to inherited biological factors, the biological factors (such as endocrinological influences) are in turn shaped and modified by learning through the process of maturation. Since maturation is inevitably a social process (given that it relies upon social interaction), Davenport indicates that regardless of our biological "potentialities," it must take a social process to create "behavior patterns that are uniform enough from individual to individual, to permit sexual interaction" (Davenport, 1976 , p. 117). Hence, without a shared social language, human sexual behavior is unlikely to occur.

If human sexual behavior has always been the product of social forces, than variability in human sexual behavior must obviously result from cultural differences. The extent of social forces is also evident in the fact that human sexual behavior often becomes loaded with special cultural meaning and relevancies which have no direct relationship to sexual gratification or reproduction. Of course, this finding is not unique to sex, but is also evident with eating and food, both of which have a clear biological foundation yet enormous cultural variability (Davenport, 1976).

The purpose of the present investigation is to examine cultural differences in sexual standards and the process of acculturation, using 
Japanese-Americans as the referent group. Japanese-Americans have been selected for study because of their generational, ethnic, and social structure. That is, since ethnicity is easily defined, generational groups are highly structured, and their social identity is basically middle class, Japanese-Americans are structurally amenable to questions of acculturation and assimilation, especially in terms of cross-generational patterns.

Kitano (1976) indicates that generation is particularly relevant to Japanese-Americans, in terms of both self-identity and shared experiences. For the present study, three generations will be included: the Issei, the Nisei, and the Sansei. These groups can be summarized in the following manner. The major influx of Japanese immigrants to the United States occurred between 1890 and 1924, the eventual decline being attributable to the passage of a national immigration bill. This relatively homogenous population immigrated to the West Coast from Hawaii and Japan, seeking cither work (males) or marriage (females). This entire group was termed Issei, or first generation (Kitano, 1976).

The term Nisei was used for children of the Issei. The Nisei were born between 1910 and 1940 and are generally more "Americanized" than their parents. This group was also greatly restricted by the prejudice and hostility associated with World War II, especially in terms of the disruption of family life and economic opportunity during the evacuation to relocation centers (Kitano, 1976).

The third generation of Japanese-Americans are known as Sansei. They were born after World War II and are presently the college-age and young-married generation. This generation is also the most acculturated of the three groups (Kitano, 1976).

The present study is hypothesizing a change in sexual standards across the three generations, approximating a bicultural adaptation (Kitano, 1976). Thus, although it is expected that there will be a liberalization of sexual attitudes across the three generations (which would be consistent with "Americanization") and a tendency toward greater consonance in sexual attitudes across the three generations in comparison with matched Caucasian-American controls, meaningful differences are also expected to emerge, even for the Sansei. Thus, although we expect strong evidence of acculturation, we also expect cultural variability, given the strong ethnic identification among Japanese-Americans, which tends to reinforce within group norms. Where gender differences do occur, liberalization and consonance are expected to be greater for Japanese-American men, since they tend to have a larger social network and greater flexibility in their sex role (Asayama, 1975).

Sex guilt was chosen as the personality variable under study. There were two reasons for favoring this concept. First, there is a long line of research which has indicated that sex guilt is of considerable significance for sexual functioning. For instance, subjects higher in sex guilt report limiting their sexual participation to the less intimate forms of 
sexual expression (Abramson \& Mosher, 1975; Mosher \& Cross, 1971), recall less birth control information (Schwartz, 1973), spend less time reading erotic literature (Schill \& Chapin, 1972), and so on. More importantly, however, sex guilt is also a concept of considerable relevance to the Japanese-American. For instance, although Japan has witnessed a cultural revolution, negative affect and conventionality still surround sexual issues (Asayama, 1975). Moreover, the suppression of sexuality is not limited to Japan, but extends to the Japanese-American as well (Connor, 1975, 1976). Thus, sex guilt is a subtantive issue, with direct relevance to both cultures under study. Finally, sex guilt was chosen because of the availability of a psychometrically sound sex guilt scale (Mosher, 1966, 1979) which was deemed inoffensive to both elderly and Asian populations. Incidently, our tendency to favor a personality measure over a behavioral measure also reflects this ethical consideration (Abramson, 1977).

\section{METHOD}

\section{Subjects}

The subjects were 62 Japanese-Americans and 82 Caucasian-American controis. Subjects were obtained from the metropolitan Los Angeles area, where Japanese-Americans comprise $1.94 \%$ of the total population and $54 \%$ of the Asian population (based on the 1970 census). The breakdown by generational category is as follows: Issei- 6 male, 9 female (total 15); Caucasian-American controls-11 male, 15 female (total 26); Nisei-13 male, 15 female (total 28); Caucasian-American controls-23 male, 16 female (total 39); Sansei-9 male, 10 female (total 19); Caucasian-American controls-23 male, 16 female (total 39).

The subjects were recruited in the following manner. The Isseis were obtained through the Nutrition Program for the Elderly. This is a federally subsidized project, which is supported in part by the local comnunity within Little Tokyo. The Nutrition Program for the Elderly is housed in a low-rent apartment complex which is used exclusively for elderly Japanese-Americans. The Isseis ranged in age from 61 to 89 , with a mean of 77 years. Individual income was below $\$ 10,000$ for every subject, and very few had higher than a junior high school education. Where the Caucasian controls are concerned, they were also obtained from a community-based housing project for the elderly. These subjects ranged in age from 65 to 83 , with a mean of 70 years. Every individual income was below $\$ 10,000$, and no subject had a higher than high school education. When both of these groups were tested, approximately $70 \%$ of the total population agreed to participate (Isseis $71 \%$, controls $73 \%$ ).

The Niseis were obtained from two sources. The first was a social support group associated with a local community center. The second source was a Nisei bowling league. The Niseis ranged in age from 40 to 68 , with the mean age being 52.5 years. The individual income ranged from $\$ 10,000$ to $\$ 20,000$ (mean $=\$ 19,000$ ), with the majority of people being nonprofessionals. Several had college degrees. The Caucasian controls were also obtained from a social support group, this one being associated with a community hospital. These subjects ranged in age from 38 to 59 , with the mean being 48 years. Individual income ranged from $\$ 10,000$ to $\$ 30,000$ (mean $\$ 20,000$ ), with the majority being nonprofessionals. Several had college or professional degrees. When both groups were tested, approximately $70 \%$ of the total population agreed to participate (Niseis $70 \%$, controls $74 \%$ ).

The Sanseis were obtained from Asian sororities and fraternities on the UCLA campus. These college students ranged in age from 18 to 21 , with mean being 20 years. The 
Caucasian controls were also obtained from sororities and franternities on the UCLA campus. They ranged in age from 17 to 23 , with the mean being 20.5 years. Every subject approached within both ethnic groups agreed to participate. Furthermore, there were no significant differences in age, income, or education between any of the Japanese-Americans samples and their Caucasian American controls.

\section{Procedure}

The sex guilt subscale of the Mosher Forced-Choice Guilt Inventory (Mosher, 1966), which consists of 28 forced-choice items that have a corrected split-half reliability of 0.97 , was used. An item example is as follows:

As a child, sex play:

A. was a big taboo and I was deathly afraid of it.

B. was common without guilt feelings.

The Mosher sex guilt subscale was also translated into Japanese. To test for the accuracy of translation, a second translator retranslated the scale back into English. The Japanese scale was used for the Issei population, although in every Japanese-American sample, subjects had the option of either the English or Japanese versions.

All subjects were tested individually or in small groups. For the Issei and Nisei samples, plus their controls, preliminary contact was established prior to testing. At this time, the exact nature of the study was explained and sample questionnaires were distributed to an organizational representative. This representative was informed that this study was being conducted under the auspices of the UCLA psychology department.

At the time of testing, our contact person provided a brief description of the study. which was later supplemented by one of our experimenters. The experimenters, of whom there were 6, were the same race as the subjects (Abramson, Goldberg, Mosher, Abramson, \& Gottesdiener, 1975). Subjects were infromed that participation was both voluntary and annonymous (Abramson, 1977). Upon completion of the Mosher Sex Guilt scale, subjects were explained the nature of the study and asked if they had any additional questions. Very few questions were raised, although some subjects expressed interest in the results (Perry \& Abramson, 1980).

The Sansei and college-aged controls were tested individually. Experimenters approached subjects with an explanation of the study and indicated the time needed to complete the questionnaire. All subjects approached agreed to volunteer participation. Experimenters were forewarned about the problems associated with self-selection and were therefore asked to recruit as many subjects as possible, at different times, until our quota was filled. Subjects participated anonymously and were allowed to shuffle completed questionnaires to avoid recognition according to order (i.e., being on top of the pile). Subjects were than thanked for their participation and provided with a name and phone number to contact if they were interested in the results (Perry \& Abramson, 1980).

\section{RESULTS}

Sex guilt scores ranged from -41 to +35 . These scores were transformed to a positive direction, with the lowest score being 1 and the highest score 77 . With this transformation the lower the score, the lower the sex guilt.

The data analyzed by a $2 \times 2 \times 3$ analysis of variance. Gender (male/ female), ethnicity (Japanese-American/Caucasion control), and generation (first/second/third) were the independent factors. The Mosher Sex Guilt scale was the sole dependent measure. The results of this analysis indicated that a significant main effect emerged for each independent 
factor. Thus, women expressed more sex guilt $(M-38.81, S D-23.47)$ than men $(M=29.74, S D=19.83 ; F(1,143)=4.55, p<.03)$; the Japanese-American sample $(M=38.73, S D=19.26)$ expressed more sex guilt then the Caucasian-American controls $(M=30.76, S D=$ $22.74 ; F(1,143), 8.92, p<.003)$; and the older generations expressed more sex guilt than the younger generations (first generation $M=51.43$, $S D=21.34$; second generation, $M=30.75, S D=19.42$; third generation, $M=25.18, S D=17.81 ; F(2,143),=24.58, p<.001)$. Incidently, the generations were significantly different from each other $(p$ $<.05$ ), as determined by the Scheffe test.

Although no significant interaction effects emerged, there was an interaction effect for gender and generation which approximated significance $(p<.06)$. Women of the first generation expressed more sex guilt than either of the five remaining cells $(F(2,143)=2.86, p<.06)$. Between cells comparisons were made by Scheffe test.

In Fig. 1, a graph of the sex guilt changes over the three generations is presented, with ethnicity and gender shown separately. This graph illustrates the substantial changes between the first and second generation, plus the tendency toward convergence between Caucasian men and women and the Japanese male. Although the Japanese female has liberalized her attitudes about human sexuality over the three generations, she still retains the most conservative attitudes of the samples assessed.

\section{DISCUSSION}

The results of this experiment conform quite well to our predictions. Evidence was provided for bicultural adaptation in terms of both con-

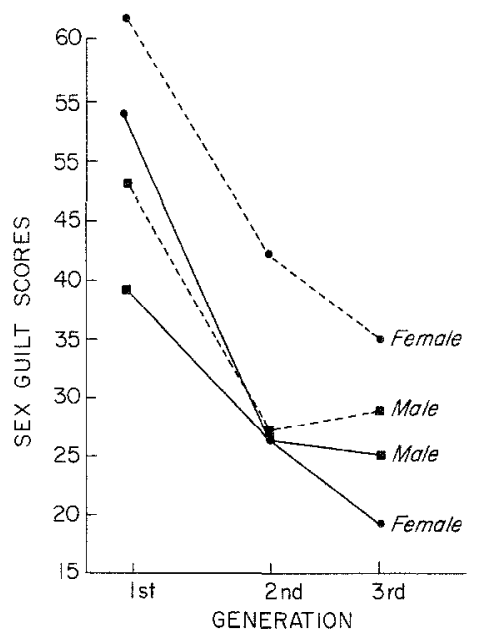

FIG. 1. A graph of the sex guilt changes over the three generations: ..., Japanese-American; _- Caucasian controls. 
vergence over generations and contemporary cultural variability. The results also approximate our predictions concerning the liberalization of sexual attitudes across the three generations, as well as gender differences illustrating decreased sex guilt in men and decreased sex guilt in Japanese-American men compared to Japanese-American women.

Kitano (1976) questions the saliency of a linear model of acculturation. That is, he is skeptical of the notion that acculturation is a linear process involving an inverse relationship between the acquisition of one culture and the relinquishment of another culture. Instead, Kitano favors an additive model, which he refers to as "bicultural adaptation." According to bicultural adaptation, relinquishing a previous culture is not synonymous with adaptation to the dominant culture. Instead, adaptation is consistent with the conexistence of both cultural values, thereby providing the individual with cultural alternatives, depending upon the time, the place, and the situation. In the present study, bicultural adaptation would mean the coexistence of two cultural identities, Japanese-American and American, both of which are assumed to complement each other (Kitano, 1976).

Although the present results are not specific to cultural identities, they are relevant to the concept of bicultural adaptation. For instance, even though the Japanese-American is considered highly acculturated in terms of endorsing American values, goals, and behaviors (Kitano, 1976), distinctive elements continue to emerge. In the first place, Japanese-Americans express significantly more sex guilt than their Caucasian-American counterparts. Although much of the variance is attributable to the Isseis and Niseis, and especially the Japanese-American women, the main effect remains the same; Japanese-Americans express more sex guilt. Incidently, this particular result is consistent with previous research (Connor, 1975, 1976) which has demonstrated that Japanese-Americans express less interest in sexuality, as measured by the Edwards Personal Preference Schedule and the Thematic Apperception Test, when compared to Caucasian-American counterparts. This particular finding is not surprising, given the significant relationship between increases in sex guilt and lessened interest in heterosexual contacts (Abramson, Mosher, Abramson, \& Woychowski, 1977; Mosher \& Cross, 1971).

Evidence of higher sex guilt among Japanese-Americans is not difficult to interpret. For instance, a number of writers have indicated that the Japanese-American family tends to deemphasize and suppress sexuality (Connor, 1976). This particular orientation is believed to be a consequence of both the intensity of and closeness within the Japanese-American family (Caudill \& Doi, 1963; Caudill \& Plath, 1974; Connor, 1976; DeVos, 1973). That is, the interconnectedness, at both the emotional and dependency levels, tends to foster stronger prohibitions against sexuality as a means of limiting the potential for sex-related conflicts among mem- 
bers in close proximity. However, besides the family dynamic, Asayama (1975) also indicates that although substantial value changes have occurred within contemporary Japan, "the old ways of thinking and the general conventional sex practices still prevail. In other words, many people still believe that sex is a disgusting thing which should be hidden from view, or that an individual should have a special sense of shame about sex" (p. 91). Although Asayama's remarks are specific to the Japanese, and not the Japanese-American, the cultural derivative of sex guilt is still evident in his words.

As illustrated in Fig. 1 the highest levels of sex guilt across the three generations are expressed by Japanese-American women. This particular finding is a consequence of both the suppression of sexuality within the Japanese-American family and the submissive role assigned to the Japanese-American woman. Thus, the Japanese-American culture socializes the suppression of sexuality in general and idealizes a nonsexualized role for women. While the severity of this conception has certainly changed over the past three decades, DeVos (1973) likened the role of the house-wife in the traditional Japanese-American family to an efficient secretary in an American business, in that an undue emphasis on sexual attractiveness would disrupt the role relationships. Of course, in preWorld War II Japan, where traditionalism prevailed, women had very limited options or social control. Yet, while there has now been a substantial improvement in the Japanese women's social and economic status, significant differences in sexual standards continue to emerge. For instance, Asayama (1975) indicates that anywhere from 75 to $90 \%$ of Japanese husbands have extramarital affairs, as compared to $3-5 \%$ of their wives. Although comparable Japanese-American data are not available, Kinsey's research (Kinsey, Pomeroy, Martin, \& Gebhard, 1953) which is now almost 3 decades old, indicated that at least $25 \%$ of American wives had extramarital affairs-a finding five times that of contemporary Japanese women. Given that the Japanese-American woman has a bicultural identity, it seems reasonable to hypothesize that the incidence of extramarital affairs is somewhere in between the two aforementioned percentages. However, given the elevated levels of sex guilt, it is also apparent that although "Americanization" has occurred, the Japanese-American woman still owes considerable allegiance to the ethnic ideals of her parents and grandparents.

The results of the present study indicated that women expressed more sex guilt than men. Furthermore, women of the first generation expressed more sex guilt than men. Although there is now a trend toward congruence in the sex guilt scores of men and women (Griffitt, 1975), Abramson and Handshumacher (1978) have suggested that this similarity is specific to a liberalized college population, whose range of scores is considerably truncated. In the present sample, which relies heavily upon noncollege 
and older populations, gender differences emerge. This difference reflects standards for acceptable sexual conduct which permit greater sexual access and flexibility for men than for women (Abramson, 1981). This is true for the older generations in general and particularly for the Japanese-American culture. Incidentally, when Fig. 1 is reviewed, it is evident that when the third, or Sansei, generations are compared, Japanese-American men and their Caucasian-American counterparts are almost identical in their sex guilt. However, the Japanese-American woman expresses the greatest sex guilt, as indicated earlier, yet her Caucasian-American counterpart expresses the least guilt. While the interaction effect was nonsignificant, the data do reflect the tendency toward convergence among college populations, plus the increasingly greater sexual freedom for Caucasian-American women.

Although there are only a limited number of cross-cultural studies on human sexuality, there are even fewer studies using elderly populations (Gurland \& Gurland, 1978). The present study is unique in that it combines both of these features. Where generation per se is concerned, significant differences emerge, with successive generations expressing less guilt over their sexual conduct. While this result undoubtedly reflects generational differences in education as well as enormous cultural changes surrounding premarital sex, contraceptive availability, sexually explicit material, and so on, a word of caution is also necessary. That is, cross-sectional studies of aging confound the effects of culture (adolescence, middle adult, older adult) with effects of aging, while keeping contemporary culture constant (Gurland \& Gurland, 1978). Thus, although evidence is provided which suggests that pronounced cultural changes concerning human sexuality have occurred over the past 70 years, educational and socioeconomic changes must also be considered.

Before concluding, there are several limitations which warrant consideration. Foremost are the limitations associated with a cross-sectional design in terms of confounding effects of age with time of birth (Schaie, 1965). Thus, attempts to understand maturational effects become incxtricably bound with generational changes in cultural values. As a solution, however, Schaie suggests the cross-sequential design, which utilizes both cross-sectional and longitudinal methods. Unfortunately, for the present study, a longitudinal approach was not particularly salient, given that the Isseis are approaching extinction. Therefore, although immigration from Japan may continue to occur, the Isseis are a fixed generational population, whose numbers only decrease with time. However, in further defense of our use of the cross-sectional design, we should also indicate that maturation per se was not under investigation. Instead, we were examining effects of acculturation over successive generations. Thus, although our Isseis and Niseis (and their controls) have been influenced by both endogenous and exogenous (or cultural) changes, these effects 
are presumably equated across ethnicity. Therefore, the question of acculturation per se is less contaminated by confounds associated with age, time of birth, and time of measurement, because these effects should be similar for both the Japanese-American and the Caucasian-American controls, given that both samples were drawn from the same geographic region and were matched for age, education, and income. Whereas other ethnic groups with less formal generational patterns may yield additional measures of control, the design of the present study provides a good match between the existing population and the experimental hypothesis (Adam, 1978).

Another potential limitation is the generalizability of the samples under study. Although the I os Angeles Japanese-American is presumed to be representative of Japanese groups of comparable size (Kitano, 1976), subtle distinctions may still emerge. Also, the use of matching has a number of limitations, including regression artifacts and generalizability (Campbell \& Stanley, 1966). However, this procedure was retained in the present study because sex guilt scores are relatively stable indices of personality (Mosher, 1979) and because the two samples (Japanese-Americans and Caucasian-Americans) are comparable on most demographic variables (Wilson \& Hosokawa, 1980). Furthermore, the study of acculturation requires comparison with a dominant culture norm. Confidence in the ecological validity of both samples will be increased through replication.

In closing, several conclusions can be tentatively drawn. First, although the Japanese-American is a highly acculturated ethnic group, within-group norms continue to persist. Thus, despite three generations of Americanization, bicultural adaptation in sexual standards appear evident, especially among Japanese-American women. On the other hand, the data also demonstrate that convergence in sexual standards is greater today than in the past, suggesting continued acculturation. Where gender differences do occur, they favor greater sexual flexibility for men in general, and for Japanesc-American men in comparison to Japanese-American women. However, this gender difference appears void for the present generation, except perhaps for the Japanese-American woman. Finally, the results suggest that pronounced cultural changes in sexual standards have occurred over the past 70 years.

\section{REFERENCES}

Abramson, P. R. The sexual system: A theory of human sexual behavior. San Francisco: Academic Press, 1982.

Abramson, P. R. Ethical requirements for research on human sexual behavior: From the perspective of participation, subjects. Journal of Social Issues, 1977, 33, 84-192.

Abramson, P. R., \& Handschumacher, I. W. The Mosher Sex Guilt Scale and the college population: A methodological note. Journal of Personality Assessment, 1978, 42, 635.

Abramson, P. R., \& Mosher, D. L. Development of a measure of negative attitudes toward masturbation. Journal of Consulting and Clinical Psychology, 1975, 43, 485-490. 
Abramson, P. R., Mosher, D. L., Abramson, S. F., \& Woychowski, B. Personality correlates of the Mosher Guilt Scales. Journal of Personality Assessment, 1977, 41, $375-382$.

Adam, J. Sequential strategies and the separation of ages, chohost, and time-of-measurement contributions to developmental data. Psychological Bulltin, 1978, 85, 1309-1316.

Asayama, S. Adolescent sex development and adult sex behavior in Japan. Journal of Sex Research, 1975, 11, 91-112.

Campbell, D. T., \& Stanley, J. C. Experimental and quasiexperimental designs for research. Chicago: Rand McNally, 1966.

Caudill, W., \& Doi, T. Interrelations of psychiatry, culture and emotion in Japan. In I. Galdston (Ed.), Man's image in medicine and anthropology. New York: Intern. Univ. Press, 1963.

Caudill, W., \& Plath, D. Who sleeps by whom? Parent-child involvement in urban Japanese families. In R. A. LeVine (Ed.), Culture and personality. Chicago: Aldine, 1974.

Connor, J. W. Value changes in third generation Japanese Americans. Journal of Personality Assessment, 1975, 39, 597-600.

Connor, J. W. Family bonds, maternal closeness and suppression of sexuality in three generations of Japanese Americans. Ethos, 1976, 4, 189-221.

Davenport, W. Sexual patterns and their regulation in a society of the Southwest Pacific. In F. A. Beach (Ed.), Sex and behavior. New York: Wiley, 1965.

Davenport, W. H. Sex in cross-cultural perspective. In F. Beach (Ed.), Human sexuality in four perspectives. Baltimore: Johns Hopkins Press, 1976.

Devos, G. Socialization for achievement. Berkeley: Univ. of California Press, 1973.

Ford, C. S., and Beach, F. A. Patterns of sexual behavior. New York: Harper \& Row, 1951.

Griffitt, W. Sexual experience and sexual responsiveness: Sex differences. Archives of Sexual Behavior, 1975, 4, 529-540.

Gurland, B. J., and Gurland, R. V. Some comments on methods of research into sex and aging. In J. Weiner and R. Green (Eds.), Methodology in sex research. Washington, D.C.: U.S. Gov. Printing Office, 1978.

Kinsey, A. C., Pomeroy, W. B., \& Martin, C. E. Sexual behavior in the human male. Philadelphia: W. B. Saunders, 1948.

Kinsey, A. C., Pomeroy, W. B., Martin, C. E., \& Gebhard, P. H. Sexual behavior in the human female. Philadelphia: W. B. Saunders, 1953.

Kitano, H. H. L. Japanese Americans: The evolution of a subculture. Englewood Cliffs, N.J.: Prentice-Hall, 1976.

Mosher, D. L. The development and multitrait-multimethod matrix analysis of three measures of three aspects of guilt. Journal of Consulting Psychology, 1966, 30, 25-29.

Mosher, D. L. The meaning and measurement of guilt. In C. E. Izard (Ed.), Emotions in personality and psychopathology. New York: Plenum, 1979.

Mosher, D. L., and Cross, H. Sex guilt and premarital sexual experiences of college students. Journal of Consulting and Clinical Psychology, 1971, 36, 27-32.

Perry, L. B., and Abramson, P. R. Debriefing: A gratuitous procedure? American Psychologist, 1980, in press.

Schaie, K. W. A general model for the study of developmental problems. Psychological Bulletin, 1965, 64, 92-107.

Schill, T. K., and Chapin, J. Sex guilt and male's preferences for reading magazines. Journal of Consulting and Clinical Psychology, 1972, 39, 516.

Schwartz, S. Effects of sex guilt and sexual arousal on the retention of birth control information. Journal of Consulting and Clinical Psychology, 1973, 41, 61-64.

Wilson, R., \& Hosokawa, B. East to America. New York: Morrow, 1980. 